\title{
Mitral valve stiffening in end-stage heart failure: Evidence of an organic contribution to functional mitral regurgitation
}

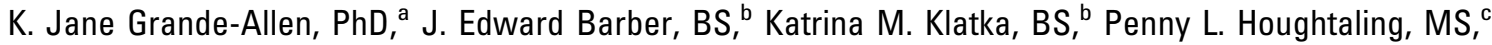 \\ Ivan Vesely, PhD, ${ }^{\mathrm{b}}$ Christine $\mathrm{S}$. Moravec, $\mathrm{PhD}{ }^{\mathrm{d}, \mathrm{f}}$ and Patrick M. McCarthy, $\mathrm{MD}^{\mathrm{e}, \mathrm{f}, \mathrm{g}}$
}

From the Department of Bioengineering, ${ }^{\mathrm{a}}$ Rice University, Houston, Tex; the Departments of Biomedical Engineering, ${ }^{\text {b }}$ Biostatistics, ${ }^{\mathrm{c}}$ Cardiovascular Medicine, ${ }^{\mathrm{d}}$ and Thoracic and Cardiothoracic Surgery ${ }^{\mathrm{e}}$ and the Kaufman Center for Heart Failure, Cleveland Clinic Foundation, Cleveland, Ohio; and Northwestern Cardiovascular Institute, ${ }^{\mathrm{g}}$ Chicago, Ill.

This project was supported by the National Institutes of Health (1-F32-HL10228) and an American Heart Association Scientist Development Grant (0235216N).

Received for publication Aug 23, 2004; revisions received April 7, 2005; accepted for publication April 25, 2005

Address for reprints: K. Jane Grande-Allen, $\mathrm{PhD}$, Department of Bioengineering MS 142, Rice University, PO Box 1892, Houston, TX 77251-1892 (E-mail: grande@ rice.edu).

J Thorac Cardiovasc Surg 2005;130:783-90

$0022-5223 / \$ 30.00$

Copyright $\odot 2005$ by The American Association for Thoracic Surgery

doi:10.1016/j.jtcvs.2005.04.019
Objective: Mitral regurgitation is a complication for many patients with congestive heart failure. Although this regurgitation is considered purely functional, we hypothesize that the alterations in cardiac geometry and function induce dysfunctional remodeling of the mitral valve, which can be demonstrated by alterations in the material behavior of the leaflets and chordae.

Methods: Mitral leaflets and chordae from 23 valves from transplant recipient hearts (11 with dilated and 12 with ischemic cardiomyopathy) and from 21 normal valves (from autopsy) were mechanically tested.

Results: Radially oriented anterior mitral leaflet strips from failing hearts were $61 \%$ stiffer and $23 \%$ less viscous on average than those from autopsy control hearts. The mean stiffness of circumferentially oriented anterior leaflet strips was 50\% higher than that of control hearts. Leaflet extensibility was reduced $35 \%$ overall. Likewise, the failing heart chordae were an average of $16 \%$ stiffer (all $P \leq .05$ ).

Conclusions: Mitral valves in congestive heart failure have significantly altered mechanics that suggest that the tissue is permanently distended and fibrotic and might be unable to stretch sufficiently to cover the valve orifice. These material changes in the valve tissues accompany the biochemical alterations in extracellular matrix composition that we have previously reported. Our finding of leaflet and chordal remodeling suggests that mitral regurgitation in patients experiencing heart failure might not be purely functional and that these mitral valves should not be considered normal. Moreover, there are implications for strategies of mitral valve surgery or percutaneous approaches in this patient population.

$\mathrm{M}$ itral valve dysfunction occurs in 55\% to $75 \%$ of patients with congestive heart failure (CHF) presenting as ischemic or idiopathic dilated cardiomyopathy. ${ }^{1-4}$ The prognosis is poor for all patients with CHF but is especially poor for patients with mitral regurgitation (MR), who have significantly more complications ${ }^{1,3}$ and survival 2 -fold ${ }^{1,5}$ to $10-$ fold $^{3}$ lower than that of patients without MR. Survival of patients with even mild MR is only half that of patients with no MR. ${ }^{1}$ The occurrence of MR in these patients has long been perceived to be primarily a functional consequence of the altered cardiac geometry. ${ }^{6,7}$ The explanation is that there is nothing wrong with the valve itself but that it is being distorted by the dilatation of the ventricles, the valve annulus, or both. This interpretation has largely been based on observations that the mitral valves appear qualitatively normal on echocardiographic and gross morphologic examinations. In animal models, however, sustained alteration of the normal valvular loading patterns was shown to affect the valvular microstructure, ${ }^{8-10}$ resulting in regurgitation that might have been partly organic, as opposed to purely functional. On the basis of these previous studies, our hypothesis is that the alterations in cardiac geometry and function found in CHF will disturb the normal mitral valve loading and consequently induce 
TABLE 1. Subject characteristics

\begin{tabular}{lccc}
\hline \multicolumn{1}{c}{ Group } & Subjects & Sex, F/M & Age, $\mathbf{y}^{*}$ \\
\hline Control specimens & 21 & $7 / 14$ & $48 \pm 18$ \\
Transplant specimens & 23 & $7 / 16$ & $50 \pm 15$ \\
$\quad$ Dilated & 11 & $5 / 6$ & $49 \pm 15$ \\
Ischemic & 12 & $2 / 10$ & $51 \pm 16$ \\
\hline
\end{tabular}

*Mean \pm standard deviation.

dysfunctional remodeling of the valve. Although our hypothesis is but one possible interpretation, we believe that such remodeling changes in valvular microstructure and extracellular matrix composition would be indirectly demonstrated by abnormal material behavior of the valve leaflets and chordae. Therefore, this study investigated the possibility for valvular dysfunctional remodeling by measuring the material properties of mitral valves from the explanted hearts of transplant recipients.

\section{Methods}

\section{Subjects}

Mitral valves were obtained from the recipient hearts of 23 patients undergoing heart transplantation (Table 1). The use of these tissues was approved by the institutional review board. These patients were previously given diagnoses of $\mathrm{CHF}$ on the basis of severe left ventricular systolic dysfunction and either severe left ventricular dilatation or a history of atherosclerosis, coronary artery disease, or myocardial infarction. Ischemic cardiomyopathy (ICM; $n=12$ ) was distinguished from dilated cardiomyopathy (DCM; $\mathrm{n}=11)$ on the basis of the presence of segmental wall motion abnormalities and significant obstructive coronary disease. Other than these distinguishing characteristics, there were no significant differences in cardiac geometry or functional parameters between subjects with ICM and subjects with DCM. All patients demonstrated typical characteristics of $\mathrm{CHF}^{5}{ }^{5}$ with a mean MR severity of $2.4 \pm$ 1.0 (Table 2). Patients who had mitral valve surgery before transplantation were excluded from the study. Normal control mitral valves were obtained from autopsy from 21 persons who died of causes other than cardiovascular or cardiac disease. The autopsy control specimens were selected according to the least time be- tween death and arrival at the morgue to minimize the differences between the harvesting of valves from the control and transplant groups. There were no significant differences in age between the $\mathrm{CHF}$ and control groups.

\section{Specimen Preparation}

The transplant recipient hearts were obtained immediately after transplantation and pathologic inspection. The mitral valve was dissected from the heart and stored in fresh Hanks balanced saline solution at $4^{\circ} \mathrm{C}$ for up to 5 days before testing. Our laboratory has previously determined that valves kept at $4^{\circ} \mathrm{C}$ retain their mechanical properties for up to 5 days. ${ }^{11}$ This finding also justifies our use of autopsy valves, which were harvested less than 24 hours postmortem from cadavers kept in cold storage $\left(4^{\circ} \mathrm{C}\right)$ as suitable and valid control specimens for the transplant valves.

All chordae longer than $10 \mathrm{~mm}$ were cut from the leaflet for testing. After removing the remainder of the chordae, the leaflets were cut into strips $(10 \times 14 \mathrm{~mm})$ oriented circumferentially or radially (parallel or orthogonal to the annular edge, respectively; Figure 1). Test specimens were noted as originating from either the posterior or anterior leaflet, and chordal insertions were characterized as marginal or basal. Several specimens were available from each valve (Table 3 ). It was not possible to obtain a circumferential and a radial sample from the same anterior leaflet. Only about half of the posterior leaflets had suitable tissue area to cut circumferential specimens. In addition, a small percentage of the valves (both transplant and control valves) were missing either the anterior or posterior leaflet because they were either retained by the pathologists or damaged during the ventricular transection. Finally, none of the control valves (unlike the transplant valves) had posterior leaflets large enough to cut radially oriented strips, and therefore differences in radial material properties of the posterior leaflets could not be tested.

\section{Mechanical Testing}

Mechanical testing was performed as previously described by Barber and colleagues. ${ }^{12,13}$ Briefly, leaflet strip thickness was measured with a digital indicator (Mitutoyo, Tokyo, Japan) and used to calculate the leaflet cross-sectional area. The average chordal cross-sectional area was calculated from their weight, length, and assumed density of $1.01 \mathrm{~g} / \mathrm{mL}$ (on the basis of their buoyancy in Hanks saline) measured after testing. ${ }^{13}$ Specimens

TABLE 2. Cardiac chamber dimensions and functional parameters

\begin{tabular}{lccrr}
\hline \multicolumn{1}{c}{ Measurement } & Subjects & DCM & Subjects & ICM \\
\hline MV annular diameter (4C), cm & 9 & $4.90 \pm 0.40$ & 11 & $4.59 \pm 0.56$ \\
LVISD, cm & 10 & $6.50 \pm 1.21$ & 10 & 10 \\
LVIDD, cm & 10 & $7.22 \pm 1.19$ & $10 \pm 1.18$ \\
IVS thickness, cm & 10 & $0.93 \pm 0.19$ & 10 & $6.91 \pm 1.03$ \\
PW thickness, cm & 10 & $1.08 \pm 0.29$ & 11 & $0.93 \pm 0.28$ \\
LA diameter, cm & 10 & $4.65 \pm 0.78$ & 11 & $0.93 \pm 0.20$ \\
MR, grade 0-4 & 10 & $2.15 \pm 1.16$ & 12 & $2.05 \pm 0.59$ \\
Ejection fraction, \% & 10 & $18.0 \pm 5.21$ & $21.1 \pm 8.75$
\end{tabular}

Data are presented as means \pm standard deviation. DCM, Dilated cardiomyopathy; ICM, ischemic cardiomyopathy; $M V$, mitral valve; $4 C, 4$-chamber; $L V I S D$, left ventricular internal systolic diameter, $L V I D D$, left ventricular internal diastolic diameter; IVS, intraventricular septum; $P W$, posterior wall; $L A$, left atrial; $M R$, mitral regurgitation. 


\section{Normal (Autopsy Controls)}
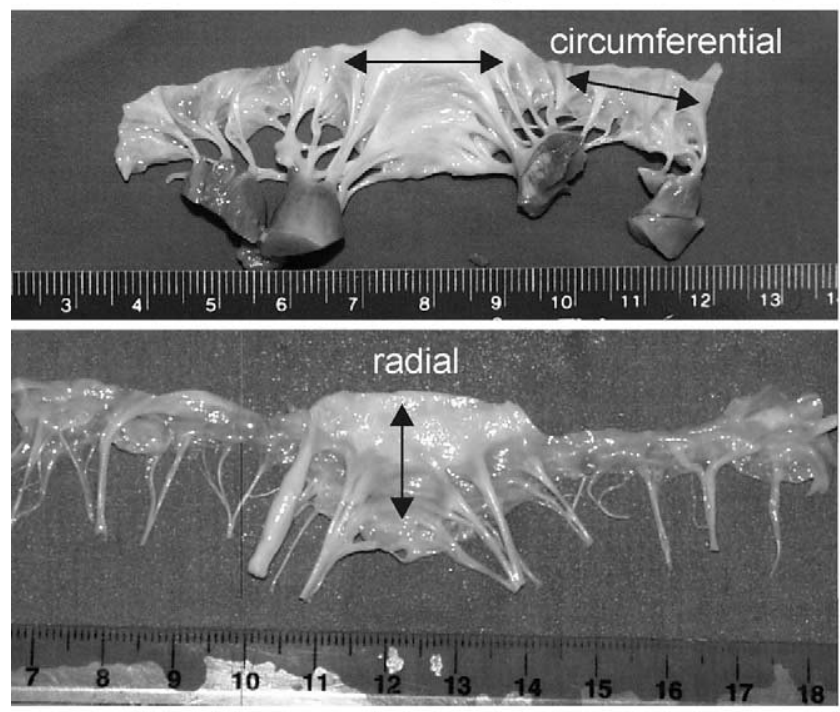

\section{CHF (Transplant Recipients)}
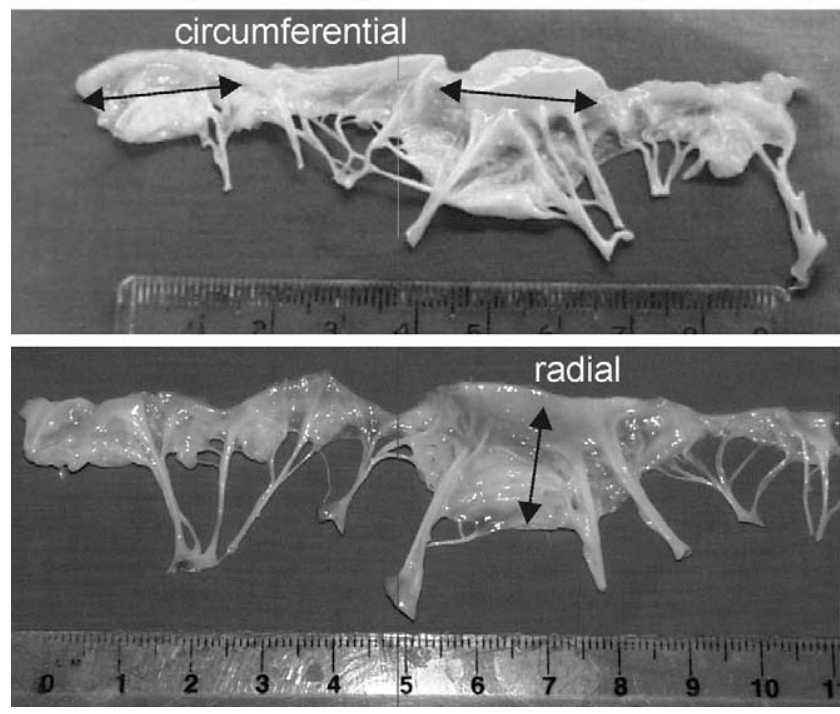

Figure 1. Mitral valves removed from heart transplant recipients (lower) show gross similarity to normal mitral valves obtained from autopsies (upper). The circumferential and radial directions of the valve are also indicated.

were gripped at both ends and placed in a servohydraulic tester (Model 8511; Instron, Canton, Mass). During testing, specimens were immersed in Hanks saline $\left(37^{\circ} \mathrm{C}\right)$. Tissue was preconditioned until the load-displacement curves were repeatable (approximately 10 cycles). Immediately after preconditioning, one load-elongation cycle was recorded. After a stress-relaxation test (100 seconds) was performed to assess viscoelasticity, the specimens were stretched to failure.

\section{Data and Statistical Analysis}

All data were examined in customized Mathematica programs (Wolfram Research, Champaign, Ill) to obtain stiffness, extensibility, stress relaxation, and failure parameters, as described previously. ${ }^{12,13}$ Stiffness was the slope of the elongation curve, expressed both as elastic modulus (kiloPascals; normalized to measured tissue cross-sectional area) and as tension (Newtons per meter; normalized to idealized tissue width of leaflet strips [10 $\mathrm{mm}]$ or chordae $[1 \mathrm{~mm}])$. Extensibility was determined as the tissue strain before the collagen fibers became fully uncrimped and the tissue stiffened. The slope of the stress-relaxation curve (load vs log time) was calculated to measure tissue viscosity.

Descriptive summary statistics are presented as means and standard deviations. Group comparisons of patient characteristics were made by using the $\chi^{2}$ and Wilcoxon rank sum tests. Repeated-measures analyses were performed (SAS PROC MIXED; SAS Institute, Inc, Cary, NC) to account for the lack of independence from multiple specimens evaluated from the same valve. Univariate models were initially formed to test group differences (ICM, DCM, and control) within leaflet and chordal subgroups. Thereafter, multivariable mixed models were developed for overall leaflet and chordae groups to evaluate group effects and interactions while adjusting for confounders (diagnosis, leaflet origin, chordal insertion, and test strip orientation). Within the CHF group, patient characteristics of age, sex, diabetes, extent of CAD, and cholesterol, as well as heart weight, posterior wall thickness, and grade of MR, were also considered for a propensity analysis. Adjusted $P$ values have been provided. All statistical testing was 2-tailed, with a significance level of .05 , and was performed with SAS version 8.2 (Cary, NC).

\section{Results}

\section{Propensity Analysis}

The 2 CHF groups (ICM and DCM) did not differ with respect to any of the explanatory factors that were considered, and there was little predictive value from the multivariable model. Therefore, propensity adjustments were not included in further mixed-model analyses that are presented here. Among all CHF valves, however, advanced age $(P=$ $.009)$ and diabetes $(P=.02)$ were related to increased leaflet thickness. Posterior wall thickness had an inverse association with leaflet thickness $(P=.007)$ and a positive association with elastic modulus $(P=.04)$.

\section{Physical Properties}

Leaflet strips cut from the $\mathrm{CHF}$ valves were thinner than control anterior and posterior leaflets (Tables 3 and 4). Anterior leaflet strips from patients with DCM were thinnest $(P=.02)$, with a mean thickness $10 \%$ less than that for ICM anterior leaflets. Likewise, chordae from the CHF hearts also had slightly smaller cross-sectional areas than normal control chordae $(P=.08$, Table 3$)$.

\section{Material Properties}

Radially and circumferentially oriented anterior leaflet strips from CHF hearts were significantly stiffer (stiffness 
TABLE 3. Physical and mechanical properties

\begin{tabular}{|c|c|c|c|c|}
\hline & \multicolumn{2}{|c|}{ Anterior leaflet } & \multirow{2}{*}{$\begin{array}{c}\text { Posterior leaflet: } \\
\text { Circumferential }\end{array}$} & \multirow[b]{2}{*}{ Chordae } \\
\hline & Circumferential & Radial & & \\
\hline \multicolumn{5}{|c|}{ No. of specimens (no. of valves) } \\
\hline Control & $13(10)$ & $19(11)$ & $13(11)$ & $82(13)$ \\
\hline All transplants & $12(10)$ & $15(10)$ & $14(11)$ & $124(21)$ \\
\hline Dilated & $7(6)$ & $7(5)$ & $6(4)$ & $56(9)$ \\
\hline Ischemic & $5(4)$ & $8(5)$ & $8(7)$ & $68(12)$ \\
\hline \multicolumn{5}{|c|}{ Thickness, mm (cross-sectional area for chordae, $\mathrm{mm}^{2}$ ) } \\
\hline Control & $2.15 \pm 1.14$ & $1.80 \pm 0.38$ & $1.77 \pm 0.39$ & $3.16 \pm 3.12$ \\
\hline All transplants & $1.39 \pm 0.36$ & $1.33 \pm 0.37^{*}$ & $1.57 \pm 0.49$ & $1.70 \pm 1.76$ \\
\hline Dilated & $1.32 \pm 0.28$ & $1.28 \pm 0.49$ & $1.57 \pm 0.45$ & $1.39 \pm 1.24$ \\
\hline Ischemic & $1.49 \pm 0.47$ & $1.37 \pm 0.25$ & $1.56 \pm 0.55$ & $2.24 \pm 2.29$ \\
\hline \multicolumn{5}{|c|}{ Extensibility, \% strain } \\
\hline Control & $23.7 \pm 15.5$ & $22.5 \pm 9.6$ & $38.4 \pm 14.7$ & $12.3 \pm 8.8$ \\
\hline All transplants & $16.8 \pm 9.1$ & $16.0 \pm 10.7$ & $30.9 \pm 15.0$ & $9.7 \pm 8.8$ \\
\hline Dilated & $16.0 \pm 10.3$ & $14.7 \pm 5.9$ & $33.0 \pm 14.1$ & $9.1 \pm 10.5$ \\
\hline Ischemic & $18.0 \pm 8.1$ & $17.2 \pm 14.0$ & $29.3 \pm 16.4$ & $10.1 \pm 7.3$ \\
\hline \multicolumn{5}{|c|}{ Stiffness, N/m (N/mm for chordae) } \\
\hline Control & $6070 \pm 2140$ & $3840 \pm 907$ & $5510 \pm 1460$ & $52.3 \pm 14.7$ \\
\hline All transplants & $9090 \pm 2280^{*}$ & $6170 \pm 1620^{*}$ & $6250 \pm 1910$ & $60.8 \pm 27.9^{*}$ \\
\hline Dilated & $9010 \pm 1700$ & $7100 \pm 1780$ & $5760 \pm 1370$ & $58.8 \pm 16.7$ \\
\hline Ischemic & $9200 \pm 3160$ & $5360 \pm 958$ & $6630 \pm 2250$ & $62.4 \pm 3.46$ \\
\hline \multicolumn{5}{|c|}{ Elastic modulus, $\mathrm{kPa}$ (MPa for chordae) } \\
\hline Control & $3550 \pm 2050$ & $2292 \pm 827$ & $3390 \pm 1660$ & $67.4 \pm 116.9$ \\
\hline All transplants & $7150 \pm 3360^{*}$ & $5031 \pm 1918^{*}$ & $4340 \pm 1900$ & $80.4 \pm 73.1$ \\
\hline Dilated & $7210 \pm 2530$ & $6092 \pm 1941$ & $3930 \pm 1560$ & $85.6 \pm 72.2$ \\
\hline Ischemic & $7060 \pm 4640$ & $4103 \pm 1422$ & $4640 \pm 2160$ & $72.3 \pm 74.9$ \\
\hline \multicolumn{5}{|c|}{ Relaxation slope, N/(m log [time]) } \\
\hline Control & $11.87 \pm 3.54$ & $12.53 \pm 3.01$ & $10.19 \pm 2.46$ & $7.16 \pm 3.19$ \\
\hline All transplants & $10.32 \pm 2.95$ & $9.70 \pm 2.61^{*}$ & $11.18 \pm 1.97$ & $6.63 \pm 2.36$ \\
\hline Dilated & $10.44 \pm 3.24$ & $10.15 \pm 2.99$ & $10.97 \pm 1.38$ & $7.25 \pm 2.81$ \\
\hline Ischemic & $10.15 \pm 2.86$ & $9.32 \pm 2.37$ & $11.34 \pm 2.4$ & $6.26 \pm 1.99$ \\
\hline \multicolumn{5}{|c|}{ Failure strain, $\%$ strain } \\
\hline Control & $39.3 \pm 18.7$ & $56.5 \pm 19.2$ & $60.4 \pm 17.1$ & $32.3 \pm 12.3$ \\
\hline All transplants & $36.8 \pm 11.6$ & $42.5 \pm 23.4$ & $53.9 \pm 15.7$ & $31.8 \pm 13.2$ \\
\hline Dilated & $39.2 \pm 13.8$ & $40.4 \pm 16.1$ & $55.2 \pm 9.2$ & $32.3 \pm 15.4$ \\
\hline Ischemic & $33.3 \pm 7.8$ & $44.3 \pm 29.5$ & $52.9 \pm 19.4$ & $31.5 \pm 11.3$ \\
\hline \multicolumn{5}{|l|}{ Failure load, g } \\
\hline Control & $1550 \pm 795$ & $1090 \pm 697$ & $741 \pm 252$ & $1320 \pm 781$ \\
\hline All transplants & $1880 \pm 900$ & $1240 \pm 441$ & $823 \pm 379$ & $1420 \pm 822$ \\
\hline Dilated & $1785 \pm 739$ & $1430 \pm 499$ & $704 \pm 367$ & $1318 \pm 820$ \\
\hline Ischemic & $2010 \pm 1170$ & $1040 \pm 290$ & $913 \pm 386$ & $1510 \pm 818$ \\
\hline \multicolumn{5}{|c|}{ Failure tension, $\mathrm{N} / \mathrm{m}(\mathrm{N} / \mathrm{mm}$ for chordae) } \\
\hline Control & $1520 \pm 780$ & $1070 \pm 684$ & $727 \pm 248$ & $12.94 \pm 7.67$ \\
\hline All transplants & $1840 \pm 883$ & $1210 \pm 433$ & $808 \pm 372$ & $13.96 \pm 8.06$ \\
\hline Dilated & $1751 \pm 725$ & $1404 \pm 490$ & $691 \pm 360$ & $12.93 \pm 8.05$ \\
\hline Ischemic & $1970 \pm 115$ & $1023 \pm 285$ & $896 \pm 379$ & $14.81 \pm 8.03$ \\
\hline \multicolumn{5}{|c|}{ Failure stress, $\mathrm{kPa}$ (MPa for chordae) } \\
\hline Control & $881 \pm 592$ & $661 \pm 402$ & $450 \pm 278$ & $14.4 \pm 26.7$ \\
\hline All transplants & $1400 \pm 798$ & $978 \pm 419$ & $541 \pm 271$ & $17.2 \pm 16.4$ \\
\hline Dilated & $1380 \pm 634$ & $1170 \pm 464$ & $449 \pm 186$ & $17.4 \pm 15.5$ \\
\hline Ischemic & $1430 \pm 1070$ & $791 \pm 303$ & $609 \pm 315$ & $16.9 \pm 17.9$ \\
\hline
\end{tabular}

Data are presented as means \pm standard deviation. $* P<.05$, congestive heart failure combined versus autopsy control. 
TABLE 4. Mixed model effects for physical and mechanical leaflet properties

\begin{tabular}{|c|c|c|c|}
\hline \multicolumn{4}{|c|}{ Thickness } \\
\hline Effect & Estimate & Standard error & $P$ value \\
\hline Intercept & 1.938 & 0.151 & $<.0001$ \\
\hline$D x-I C M$ & -0.399 & 0.220 & .08 \\
\hline Dx- DCM & -0.542 & 0.220 & .02 \\
\hline Anterior leaflet & -0.118 & 0.139 & .40 \\
\hline Radial & 0.033 & 0.152 & .82 \\
\hline \multicolumn{4}{|c|}{ Extensibility } \\
\hline Effect & Estimate & Standard error & $P$ value \\
\hline Intercept & 38.420 & 2.891 & $<.0001$ \\
\hline$D x-I C M$ & -7.759 & 3.869 & .05 \\
\hline Dx- DCM & -8.180 & 3.890 & .04 \\
\hline Anterior leaflet & -15.215 & 3.253 & $<.0001$ \\
\hline Radial & -0.253 & 3.315 & .94 \\
\hline \multicolumn{4}{|c|}{ Stiffness } \\
\hline Effect & Estimate & Standard error & $P$ value \\
\hline Intercept & 4730 & 412 & $<.0001$ \\
\hline Dx- ICM & 1960 & 522 & .0006 \\
\hline Dx- DCM & 2390 & 525 & $<.0001$ \\
\hline Anterior leaflet & 1840 & 491 & .0005 \\
\hline Radial & -2720 & 483 & $<.0001$ \\
\hline \multicolumn{4}{|c|}{ Elastic modulus } \\
\hline Effect & Estimate & Standard error & $P$ value \\
\hline Intercept & 2470 & 506 & $<.0001$ \\
\hline Dx- ICM & 2190 & 641 & .0016 \\
\hline Dx- DCM & 2990 & 645 & $<.0001$ \\
\hline Anterior leaflet & 1760 & 584 & .005 \\
\hline Radial & -1940 & 585 & .002 \\
\hline \multicolumn{4}{|c|}{ Relaxation slope } \\
\hline Effect & Estimate & Standard error & $P$ value \\
\hline Intercept & 10.419 & 0.555 & $<.0001$ \\
\hline \multicolumn{4}{|l|}{$D x-I C M$} \\
\hline \& anterior & -2.548 & 1.009 & .016 \\
\hline \multicolumn{4}{|l|}{ Dx- DCM } \\
\hline$\&$ anterior & -1.803 & 0.997 & .07 \\
\hline Anterior leaflet & 1.613 & 0.854 & .07 \\
\hline Radial & 0.493 & 0.781 & .53 \\
\hline \multicolumn{4}{|c|}{ Failure strain } \\
\hline Effect & Estimate & Standard error & $P$ value \\
\hline Intercept & 61.200 & 4.313 & $<.0001$ \\
\hline Dx- ICM & -7.972 & 5.500 & .15 \\
\hline Dx- DCM & -7.705 & 5.527 & .17 \\
\hline Anterior leaflet & -20.074 & 5.102 & .0003 \\
\hline Radial & 13.814 & 5.046 & .0090 \\
\hline
\end{tabular}

TABLE 4. Continued

\begin{tabular}{|c|c|c|c|}
\hline \multicolumn{4}{|c|}{ Failure load } \\
\hline Effect & Estimate & Standard error & $P$ value \\
\hline Intercept & 652 & 145 & $<.0001$ \\
\hline Dx- ICM & 173 & 186 & .36 \\
\hline Dx- DCM & 210 & 184 & .26 \\
\hline Anterior leaflet & 992 & 173 & $<.0001$ \\
\hline Radial & -603 & 171 & .0010 \\
\hline \multicolumn{4}{|c|}{ Failure tension } \\
\hline Effect & Estimate & Standard error & $P$ value \\
\hline Intercept & 639 & 142 & $<.0001$ \\
\hline Dx- ICM & 170 & 183 & .36 \\
\hline Dx- DCM & 206 & 181 & .26 \\
\hline Anterior leaflet & 973 & 169 & $<.0001$ \\
\hline Radial & -593 & 167 & .0010 \\
\hline \multicolumn{4}{|c|}{ Failure stress } \\
\hline Effect & Estimate & Standard error & $P$ value \\
\hline Intercept & 310 & 119 & .013 \\
\hline Dx- ICM & 251 & 151 & .10 \\
\hline Dx- DCM & 375 & 149 & .016 \\
\hline Anterior leaflet & 708 & 138 & $<.0001$ \\
\hline Radial & -384 & 138 & .008 \\
\hline
\end{tabular}

Effects are ischemic cardiomyopathy (ICM) and dilated cardiomyopathy (DCM) versus control, anterior versus posterior, and radial versus circumferential. Dx, Diagnosis.

and elastic modulus, both $P \leq .001)$ than autopsy control leaflets (Figure 2 and Tables 3 and 4). In the ICM diagnosis group, the leaflets were also less viscous $(P=.02)$ than control leaflets. CHF leaflets required slightly less strain to failure, although this was not statistically significant either as a combined group $(P=.08)$ or as subgroups $(P=.15$, ICM; $P=.17$, DCM; Table 4). Extensibility was lower in CHF hearts than in control hearts $(P=.05$, ICM; $P=.04$, DCM) for each leaflet test strip orientation analyzed. The leaflets from patients with DCM seemed affected the most, although there were no statistical differences found between the CHF groups; compared with the patients with ICM, the mean anterior radial stiffness was 32\% higher, the mean radial elastic modulus was $48 \%$ higher, and the mean radial failure stress was $47 \%$ higher for the patients with DCM.

As found in leaflets, the mitral valve chordae from transplant hearts were slightly less extensible and more stiff $(P=$ .05 ) than that chordae from autopsy control hearts (Figure 2 and Table 3). In particular, the mean stiffness of basal chordae from transplant hearts was $17 \%$ higher than that from normal hearts $(P=.02)$. Although the elastic modulus, like the stiffness, was higher for the CHF chordae than for control chordae, the wide variation in the chordal crosssectional area prevented the modulus difference from reaching statistical significance. There was also no difference in 
A

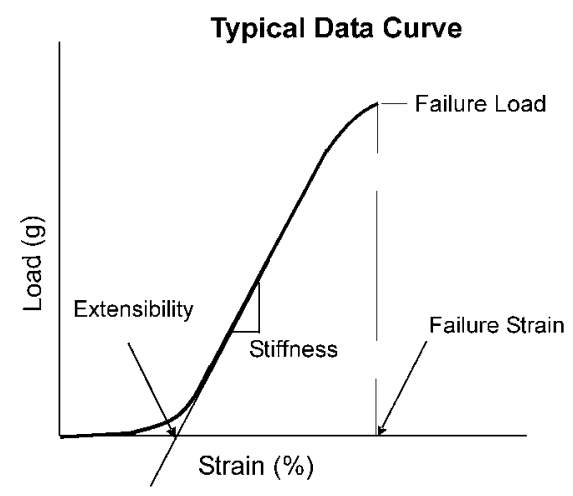

Stress Relaxation (Leaflet Radial)

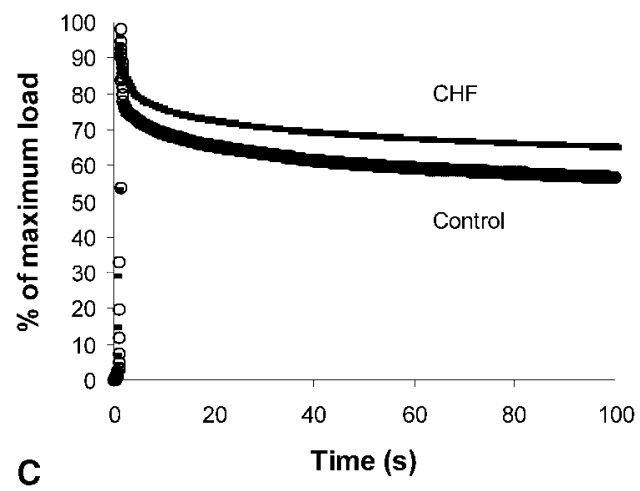

Leaflet Load-Strain Curves

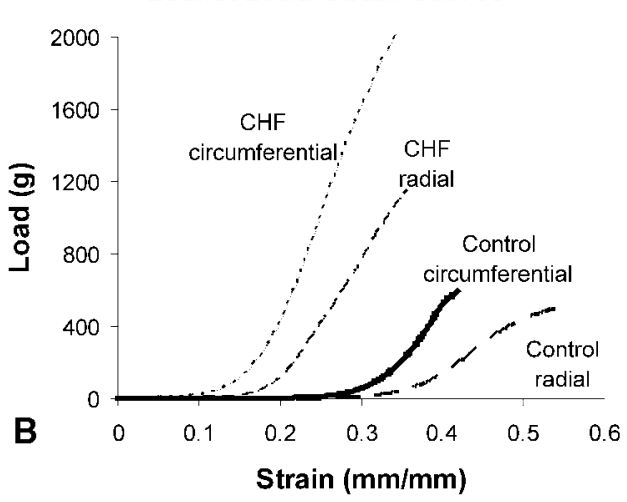

Chordal Load-Strain Curves

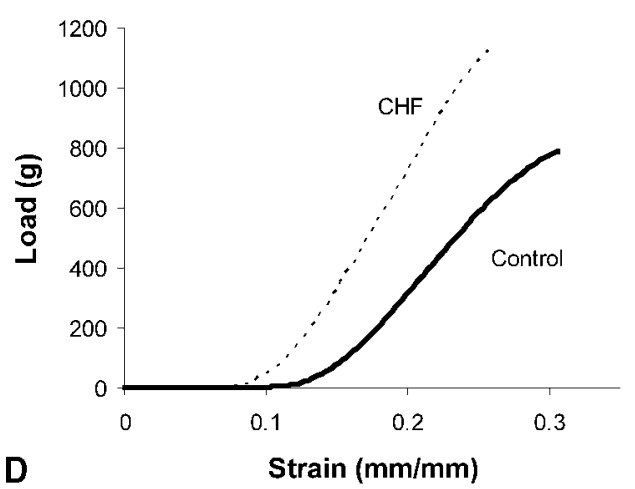

Figure 2. A, Illustration of the material properties calculated from the load-deformation data, as explained in the text. B, Representative load-strain curves from radially and circumferentially oriented leaflet strips. C, Representative stress-relaxation curves from radially oriented leaflet strips. D, Representative load-strain curves from chordae. B through D contain specimen curves most closely matching the average material properties of Table 4.

failure characteristics between the transplant and control groups. The differential diagnoses of CHF (ICM and DCM) demonstrated similar chordal mechanics.

\section{Discussion}

This study demonstrates that mitral valves from patients with CHF (whether ICM or DCM) had significantly altered material properties compared with those from a control group with the same mean age. These valves were stiffer, less extensible, and less viscous, which we believe is due to a dysfunctional remodeling response to the altered valvular loading patterns in CHF. To our knowledge, this is the first report of altered mechanics in these valves for 2 reasons. First, the MR often found in these patients is largely presumed to be functional, as opposed to organic. ${ }^{6}$ Second, these heart valves have been used as normal control valves for studies of valve biology or other valve diseases. The altered mechanics reported here contradict both of these assumptions. Furthermore, these changes appear to represent a fibrotic remodeling response that has some notable differences from the remodeling found in myxomatous ${ }^{12,13}$ or rheumatic valve disease.

There are likely both biochemical matrix remodeling and geometric causes for these material property changes in the CHF mitral valves. We recently reported that these valves have greater concentrations of collagen (15\% higher) and cells (78\% higher) and a 7\% lower concentration of water. ${ }^{14}$ We propose that the greater concentration of cells indicates an upregulation of mitogenic activity, which could be accompanied by increased matrix synthesis. Because collagens are largely responsible for providing tissue with the strength to withstand high tensile loads, ${ }^{15,16}$ the accumulation of collagen in mitral valves would increase stiffness. The loss of water, which is a major component of the extracellular matrix and contributes to tissue viscoelasticity, is likely responsible for the reduced viscous relaxation. The reduced extensibility, on the other hand, suggests that the leaflet and chordal tissue has also become permanently distended and stretched. A permanent stretch of the valve tissues would effectively reduce the amount of tissue defor- 
mation required before the collagen fibrils become uncrimped and begin to bear loads. Correspondingly, the altered material load-strain curves of the valve tissues show a leftward shift of the "crimped to uncrimped" transition region and a higher slope of the collagenous region (Figure 2 ). This material change is also not due to aging alone; valve stiffening ${ }^{17}$ and thickening ${ }^{18}$ are associated with aging, but our group of CHF valve test specimens was found to be thinner and yet stiffer than control specimens from the same age group.

These findings provide support for the theory that heart valves are not passive structures but are instead active tissues containing cells that adapt to loading or geometry outside of their normal range by remodeling the microstructural makeup of the tissue. ${ }^{8,9}$ Although this is only one possible interpretation of our data, we assert that the fibrotic change found in this study provides evidence for remodeling. Reports from clinical studies, ${ }^{14}$ animal models, ${ }^{8-10}$ and computer models ${ }^{19}$ provide additional support by showing that mitral valves exposed to chronic, acute, or simulated ventricular insults demonstrate upregulated DNA and collagen synthesis, as well as increased cell, collagen, and glycosaminoglycan concentrations and increased leaflet stresses. The resulting remodeled valves, however, might not be able to function normally in the long term.

These material property changes indicate that MR in patients with CHF might be partly organic in nature and might have serious clinical consequences. Our proposed mechanism for this MR is that because of the increased tissue stiffness, the valve cannot distend sufficiently in the radial direction to cover the valve orifice. This mechanism is consistent with a previous finite element model ${ }^{8}$ in which increased stiffness and reduced extensibility caused increased valve stresses and reduced coaptation, leading to MR. Although normal mitral valves have an inherent natural redundancy of leaflet size that enables some reduction of the coaptation region without valve leakage, ${ }^{8}$ in the setting of $\mathrm{CHF}$, an enlarged valve annulus will compound the inability of the valve to stretch sufficiently. Furthermore, these abnormal material properties might also affect the valvular closing velocities and response to $\mathrm{dP} / \mathrm{dt}$. Thus mitral valve remodeling should be incorporated into the listing of potential causes of MR. ${ }^{6}$ The progressive cycle of abnormal valvular loading, regurgitation, and remodeling is likely a factor in the adverse patient prognoses that accompany $\mathrm{MR}^{1,3,5}$ and might have implications for the surgical or percutaneous approaches to manage this patient population. Annuloplasty techniques and even edge-to-edge repair have demonstrated a high return of $3+$ or $4+M R$ in patients with ischemic MR. ${ }^{20,21}$ Percutaneous approaches to treat this type of MR will be challenging, and chord-sparing mitral valve replacement might be required more often for surgically treated patients. ${ }^{22}$
These findings of material property abnormalities in mitral valves from failing hearts also affect more basic science studies of heart valve disease. Although these valves were considered normal in such studies, their material properties, matrix, and cells are those of a remodeled tissue. Data resulting from their use should be interpreted in light of the valve origins.

This study had a number of limitations. One limitation was that due to the minimum specimen size requirements for mechanical testing, the smaller lateral scallops of the posterior leaflet could not be tested. In particular, P3, the leaflet region most likely affected by an ischemic event causing displacement of the papillary muscles, ${ }^{23}$ was not tested. Most of the posterior leaflet specimens were taken from P2, the larger central scallop. Another limitation is that we cannot delineate the relative contributions of functional and organic MR to the total MR of the patients. This goal will likely require significant animal and computer modeling studies. Finally, we were limited by the amount of patient information available on the control specimens to use in further risk-adjusted analyses.

In conclusion, we have provided the first evidence that chronic dysfunction of the heart, geometric distortion of the heart, or both, affects the material behavior of the mitral valve. These material property changes would consequently impair valve function and might worsen any existing functional MR. Thus, the diagnosis of functional MR, which characterizes the valve as a solely passive structure, might not accurately depict the valve dysfunction in patients with CHF.

We thank the cardiac transplantation teams, the surgical pathologists, the members of the Moravec laboratory, and Songhua Lin for her biostatistical contributions.

\section{References}

1. Blondheim DS, Jacobs LE, Kotler MN, Costacurta GA, Parry WR. Dilated cardiomyopathy with mitral regurgitation: decreased survival despite a low frequency of left ventricular thrombus. Am Heart J. 1991;122:763-71.

2. Capomolla S, Febo O, Gnemmi M, Riccardi G, Opasich C, Caporotondi A, et al. Beta-blockade therapy in chronic heart failure: diastolic function and mitral regurgitation improvement by carvedilol. Am Heart J. 2000;139:596-608.

3. Junker A, Thayssen P, Nielsen B, Andersen PE. The hemodynamic and prognostic significance of echo-Doppler-proven mitral regurgitation in patients with dilated cardiomyopathy. Cardiology. 1993;83:1420.

4. Smolens IA, Pagani FD, Bolling SF. Mitral valve repair in heart failure. Eur J Heart Fail. 2000;2:365-71.

5. Koelling TM, Aaronson KD, Cody RJ, Bach DS, Armstrong WF. Prognostic significance of mitral regurgitation and tricuspid regurgitation in patients with left ventricular systolic dysfunction. Am Heart J. 2002;144:524-9.

6. Levine RA, Hung J, Otsuji Y, Messas E, Liel-Cohen N, Nathan N, et al. Mechanistic insights into functional mitral regurgitation. Curr Cardiol Rep. 2002;4:125-9. 
7. He S, Lemmon JD Jr, Weston MW, Jensen MO, Levine RA, Yoganathan AP. Mitral valve compensation for annular dilatation: in vitro study into the mechanisms of functional mitral regurgitation with an adjustable annulus model. J Heart Valve Dis. 1999;8:294-302.

8. Kunzelman KS, Quick DW, Cochran RP. Altered collagen concentration in mitral valve leaflets: biochemical and finite element analysis. Ann Thorac Surg. 1998;66(suppl):S198-205.

9. Quick DW, Kunzelman KS, Kneebone JM, Cochran RP. Collagen synthesis is upregulated in mitral valves subjected to altered stress. ASAIO J. 1997;43:181-6.

10. Willems IE, Havenith MG, Smits JF, Daemen MJ. Structural alterations in heart valves during left ventricular pressure overload in the rat. Lab Invest. 1994;71:127-33.

11. Patel J. Effect of absolute specimen size on the tensile properties of porcine aortic valve tissues [Master's Thesis]. Cleveland (Ohio): Case Western Reserve University; 2003.

12. Barber JE, Kasper FK, Ratliff NB, Cosgrove DM, Griffin BP, Vesely I. Mechanical properties of myxomatous mitral valves. J Thorac Cardiovasc Surg. 2001;122:955-62.

13. Barber JE, Ratliff N, Cosgrove D, Griffin BP, Vesely I. Myxomatous mitral valve chordae. I. Mechanical properties. J Heart Valve Dis. 2001;10:320-4.

14. Grande-Allen KJ, Borowski A, Troughton R, Houghtaling P, DiPaola $\mathrm{N}$, Moravec CS, et al. Apparently normal mitral valves in heart failure patients demonstrate biochemical and structural derangements: an extracellular matrix and echocardiographic study. J Am Coll Cardiol. 2005;45:54-61.
15. Lis Y, Burleigh MC, Parker DJ, Child AH, Hogg J, Davies MJ. Biochemical characterization of individual normal, floppy and rheumatic human mitral valves. Biochem J. 1987;244:597-603.

16. Parry DAD, Craig AS. Collagen types: structure, distributions, and functions. In: Nimni ME, editor. Collagen. Volume I: biochemistry. Boca Raton (Fla): CRC Press; 1988. p. 139-56.

17. Clark R. Stress-strain characteristics of fresh and frozen human aortic and mitral leaflets and chordae tendineae. Implications for clinical use. J Thorac Cardiovasc Surg. 1973;66:202-8.

18. Sell S, Scully R. Aging changes in the aortic and mitral valves. Am J Pathol. 1965;46:345-65.

19. Kunzelman KS, Cochran RP, Chuong C, Ring WS, Verrier ED, Eberhart RD. Finite element analysis of the mitral valve. J Heart Valve Dis. 1993;2:326-40.

20. Bhudia SK, McCarthy PM, Smedira NG, Lam BK, Rajeswaran J, Blackstone EH. Edge-to-edge (Alfieri) mitral repair: results in diverse clinical settings. Ann Thorac Surg. 2004;77:1598-606.

21. McGee EC, Gillinov AM, Cohen G, Blackstone EH, Rajeswaran J, Sabik JF, et al. Recurrent mitral regurgitation after annuloplasty for functional ischemic mitral regurgitation. J Thorac Cardiovasc Surg. 2004;128:916-24.

22. Calafiore AM, Gallina S, Di Mauro M, Gaeta F, Iaco AL, D'Alessandro S, et al. Mitral valve procedure in dilated cardiomyopathy: repair or replacement? Ann Thorac Surg. 2001;71:1146-53.

23. Cochran RP, Kunzelman KS. Effect of papillary muscle position on mitral valve function: relationship to homografts. Ann Thorac Surg. 1998;66(suppl):S155-61. 